\title{
Pullout force comparison of selected screws for rigid fixation in maxillofacial surgery
}

\section{Porównanie siły wyciągającej wybranych śrub stabilizujących w chirurgii szczękowo-twarzowej}

\author{
Marcin Kozakiewicz ${ }^{A, C, E, F}$, Piotr Sołtysiak ${ }^{B, D}$ \\ Department of Maxillofacial Surgery, Medical University of Lodz, Łódz, Poland \\ A - research concept and design; $\mathrm{B}$ - collection and/or assembly of data; $\mathrm{C}$ - data analysis and interpretation; \\ $D$ - writing the article; $E$ - critical revision of the article; $F$ - final approval of article
}

Address for correspondence

Marcin Kozakiewicz

E-mail:marcin.kozakiewicz@umed.lodz.pl

\section{Funding sources}

The study was supported by the Polish Ministry of Science and Higher Education grant 0117/DIA/2014/43 and Medical University of Lodz grant 503/5-061-02/503-01.

\section{Conflict of interest}

none declared

\section{Acknowledgements}

The authors with to thank ChM Ltd. (chm.eu) for technical support in conducting the experiment.

Received on November 19, 2016 Revised on December 18, 2016 Accepted on May 13, 2017

\begin{abstract}
Background. Screws used in open reduction and internal rigid fixation need a large amount of force to effectively stabilize the plate. Currently, there is no worldwide standard screw design and there are no publications available comparing the pullout strength of different maxillofacial osteosynthesis systems.

Objectives. The aim of the study was to compare the pullout strength of different screw types.

Material and methods. The study used 75 screws made by the main manufacturers (DePuy Synthes, KLS Martin and Medartis). The screws were inserted into polyurethane up to $3.6 \mathrm{~mm}$ or $9.6 \mathrm{~mm}$ deep. The 1-100 kN Insight Material Testing System (MTS Systems Corporation), a twin-column floor-standing model for high-force applications, was used for the electromechanical measurement of the screws' axial pullout strength from the blocks of polyurethane. The method was based on the standard specification and test methods for metallic medical bone screws (ASTM F543-07 and Annex A3).
\end{abstract}

Results. Among the self-tapping microscrews $6 \mathrm{~mm}$ in length and $1.5 \mathrm{~mm}$ in diameter, DePuy Synthes screws had the greatest average pullout force $(226.0 \pm 7.52 \mathrm{~N} ; \mathrm{p}<0.05)$. Among the self-drilling $6 \mathrm{~mm} \times 1.5 \mathrm{~mm}$ microscrews, DePuy Synthes screws also had the highest score (253.6 $\pm 4.39 \mathrm{~N}$; $p<0.05$ ). Among self-tapping miniscrews $6 \mathrm{~mm}$ in length and $2.0 \mathrm{~mm}$ in diameter, Medartis screws attained the highest scores $(228.8 \pm 9.73 \mathrm{~N} ; \mathrm{p}<0.05)$. Among self-drilling $6 \mathrm{~mm} \times 2.0 \mathrm{~mm}$ screws, KLS Martin screws had the best results $(320.8 \pm 9.09 \mathrm{~N} ; \mathrm{p}<0.05)$.

Conclusions. There are significant differences in fixing force among screws of the same diameter but originating from different manufacturers.

Key words: screw, maxillofacial surgery, bone fracture treatment, pullout strength

Słowa kluczowe: Śruba, chirurgia szzzękowo-twarzowa, leczenie złamań kości, siła wyciągająca

DOI

$10.17219 / \mathrm{dmp} / 73718$

Copyright

C 2017 by Wroclaw Medical University

and Polish Dental Society

This is an article distributed under the terms of the

Creative Commons Attribution Non-Commercial License

(http://creativecommons.org/licenses/by-nc-nd/4.0/) 
Most maxillofacial traumas are attributed to traffic accidents; the runners-up are falls, sports-related injuries and violence of various kinds. Condylar fractures make up the preponderance (55\%) of mandibular fractures that are reported, but the symphyseal region, the mandibular body and the angle of the mandible are also frequently involved. ${ }^{1}$ Fracture healing is a dynamic process in which the masticatory forces slowly intensify and are taken over by the healing bone. Facial skeleton fractures typically require (closed or open) reduction. There are several aspects to be factored in when selecting the fixation type: the patient's age, the fracture site, the complexity of the injury and the approach to fracture remediation., ${ }^{2,3}$

The open reduction and internal fixation (ORIF) method has been hailed as the gold-standard approach for handling displaced fractures. It offers the possibility of reconstructing the maxillofacial region in a stable and 3-dimensional fashion. Other factors contributing to its success are better healing of the primary bone, a short recovery time and the fact that it calls for no intermaxillary fixation. To rigidly fix the material, monocortical miniplate fixation appears foolproof, superseding the somewhat obvious choice of bicortical plating for mandibular fractures. ${ }^{4}$ The choice between these 2 fixation methods determines the use of shorter or longer screws. Either way, plate stabilization is achieved by fixing screw anchorage in the bone.

High condylar neck fractures are a particularly challenging area for ORIF. Clinicians can use 2 types of material: 1) 15-17 $\mathrm{mm}$ lag screws directed through the distal neck fragment toward the mandibular head or 2) a dedicated plate and $6 \mathrm{~mm}$ screws. ${ }^{5,6}$ So far no studies have been published comparing the pullout strength of different maxillofacial ORIF systems used for that application.

The aim of this study is to compare 5 different screw types for rigid maxillofacial bone fixation from 3 worldwide manufacturers.

\section{Material and methods}

The study used 75 screws, 25 from each of 3 medical companies. The first series of screws used were made by KLS Martin GmbH \& Co. (Tuttlingen, Germany): 5 self-drilling screws $1.5 \mathrm{~mm}$ in diameter and $6 \mathrm{~mm}$ in length (Center-drive DFS $1.5 \times 6 \mathrm{~mm}$, ref. 25-668-06-09); 5 self-tapping screws $1.5 \mathrm{~mm}$ in diameter and $6 \mathrm{~mm}$ in length (Center-drive micro screw $1.5 \times 6 \mathrm{~mm}$, ref. 25-665-06-09); 5 self-tapping screws $2.0 \mathrm{~mm}$ in diameter and $6 \mathrm{~mm}$ in length (Center-drive mini screw $2 \times 6 \mathrm{~mm}$, ref. 25-662-06-09); 5 self-drilling screws $2.0 \mathrm{~mm}$ in diameter and $7.0 \mathrm{~mm}$ in length(Center-drive DFS $2 \times 7 \mathrm{~mm}$, ref. 25-669-07-09); and 5 self-tapping screws $2.0 \mathrm{~mm}$ in diameter and $17.0 \mathrm{~mm}$ in length (Center-drive mini screw $2 \times 17 \mathrm{~mm}$, ref. 25-662-17-09).
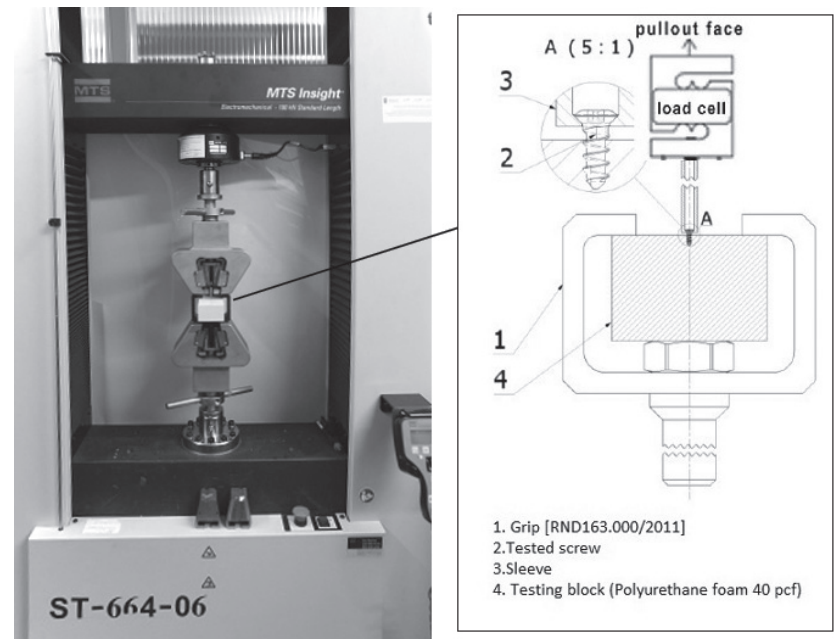

Fig. 1. The test stand and a diagram of the experimental set-up

The second screw manufacturer tested was DePuy Synthes (West Chester, USA): 5 self-drilling screws $1.5 \mathrm{~mm}$ in diameter and $6 \mathrm{~mm}$ in length (Matrix MIDFACE Screw $1.5 \mathrm{~mm}$, self-drilling, L $6 \mathrm{~mm}$, ref. 04.503.226.01C); 5 self-tapping screws $1.5 \mathrm{~mm}$ in diameter and $6 \mathrm{~mm}$ in length (Matrix MIDFACE Screw $1.5 \mathrm{~mm}$, self-tapping, L $6 \mathrm{~mm}$, ref. 04.503.206.01C); 5 self-tapping screws $2.0 \mathrm{~mm}$ in diameter and $6 \mathrm{~mm}$ in length (Matrix MANDIBLE Screw $2.0 \mathrm{~mm}$, self-tapping, L $6 \mathrm{~mm}$, ref. 04.503.406.01C); 5 self-drilling screws $2.0 \mathrm{~mm}$ in diameter and $6 \mathrm{~mm}$ in length (Matrix MANDIBLE Screw $2.0 \mathrm{~mm}$, self-drilling, L $6 \mathrm{~mm}$, ref. 04.503.506.01C); and 5 self-tapping screws $2.0 \mathrm{~mm}$ in diameter and $16.0 \mathrm{~mm}$ in length (Matrix MANDIBLE Screw $2.0 \mathrm{~mm}$, self-drilling, L $16 \mathrm{~mm}$, ref. 04.503.416.01C).

The third screw manufacturer included was Medartis AG (Basel, Switzerland): 5 self-drilling screws $1.5 \mathrm{~mm}$ in diameter and $6 \mathrm{~mm}$ in length (SpeedTip Screw, cross $1.5 \mathrm{~mm}$, L $6 \mathrm{~mm}$, ref. M-5121.06); 5 self-tapping screws $1.5 \mathrm{~mm}$ in diameter and $6 \mathrm{~mm}$ in length (1.5 Cortical Screw $06 \mathrm{~mm}$, cross, ref. M-5122.06); 5 self-tapping screws $2.0 \mathrm{~mm}$ in diameter and $6 \mathrm{~mm}$ in length (2.0 Cortical Screw 06 mm, cross, ref. M-5180.06); 5 self-drilling screws

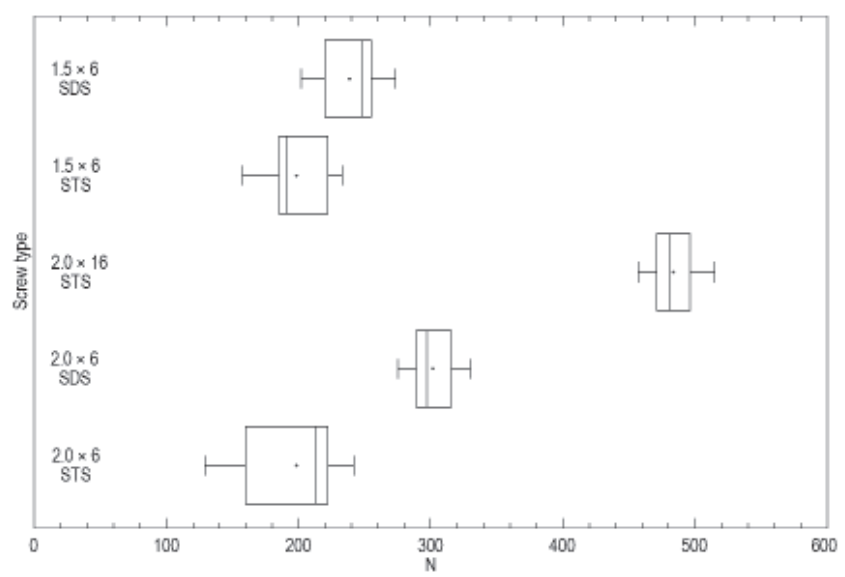

Fig. 2. The pullout strength of all tested screws. SDS: self-drilling screw; STS: self-tapping screw; N: newtons. 


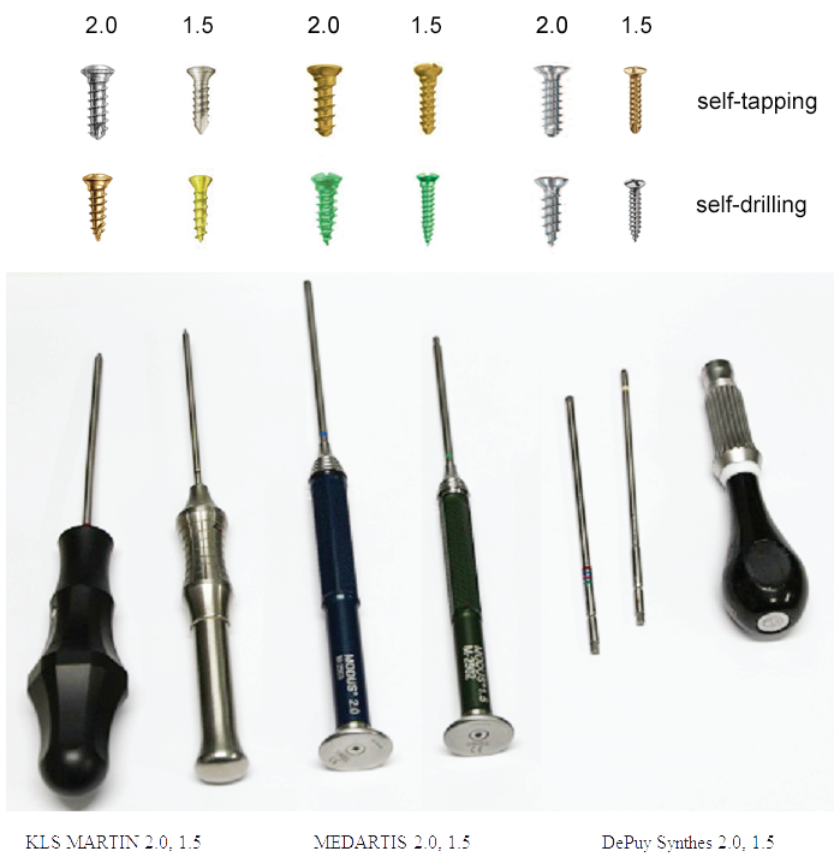

Fig. 3. The $6 \mathrm{~mm}$-long self-drilling and self-tapping screws $(2.0 \mathrm{~mm}$ and $1.5 \mathrm{~mm}$ in diameter) compared in the study. Below: screwdrivers

$2.2 \mathrm{~mm}$ in diameter and $6 \mathrm{~mm}$ in length (Cortical Screw, self-drilling, cross, $2.2 \mathrm{~mm}$, L $6 \mathrm{~mm}$, ref. M-5183.06); and 5 self-tapping screws $2.0 \mathrm{~mm}$ in diameter and $17.0 \mathrm{~mm}$ in length (2.0 Cortical Screw $17 \mathrm{~mm}$, cross, ref. M- 5180.17).

The 1-100 kN Insight Material Testing System (MTS Systems Corporation, Eden Prairie, USA), a twin-column floor-standing model for high-force applications, was used with TestWorks software (MTS Systems Corporation) for the electromechanical measurement of screw axial pullout strength from blocks of polyurethane (Fig. 1). A material similar to the human bone, the solid rigid polyurethane foam used in this experiment had a density of 40 pounds per cubic foot $(0.64 \mathrm{~g} / \mathrm{cc})$ and a thickness of $40 \mathrm{~mm}$. ASTM F1839 specifications for rigid polyurethane describe the material as having a compressive strength of $31 \mathrm{MPa}$, compressive modulus: $759 \mathrm{MPa}$; tensile strength: $19 \mathrm{MPa}$; tensile modulus: $1000 \mathrm{MPa}$; shear strength: $11 \mathrm{MPa}$; and shear modulus: $130 \mathrm{MPa}$. The polyurethane blocks were prepared and instrumented with one of the 25 screw types described above. Any blocks with wall breach were discarded.

Prior to the insertion of self-tapping screws into the polyurethane blocks, pilot holes were created in accord-

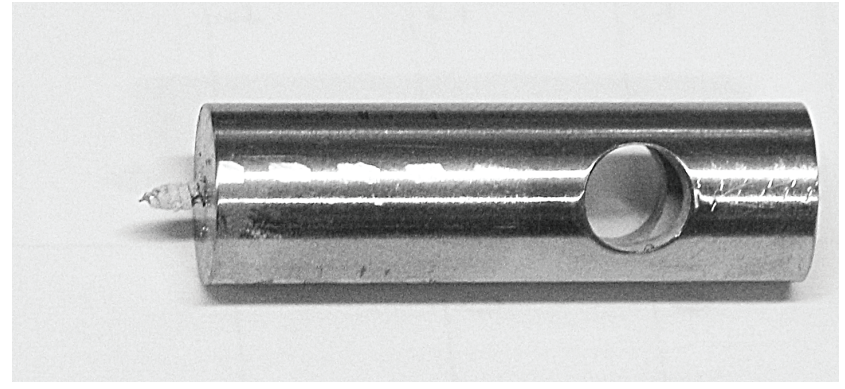

Fig. 4. A self-drilling screw after the pullout test. Note the polyurethane within the threads

ance with the manufacturers' instructions, using a $1.2 \mathrm{~mm}$ drill for screws with a diameter of $1.5 \mathrm{~mm}$ and a $1.7 \mathrm{~mm}$ drill for $2.0 \mathrm{~mm}$ screws. Self-drilling screws have a sharp tip and thread that allows penetration with no need for a drill or pilot hole to insert the screw. The manual insertion method was used with all the screws, in accordance with the manufacturers' recommendations. Insertion was perpendicular towards the anterior of the polyurethane foam, up to $3.6 \mathrm{~mm}$ deep in the case of 6-7 $\mathrm{mm}$ screws and up to $9.6 \mathrm{~mm}$ with 16-17 $\mathrm{mm}$ length screws (Fig. 3).

The mechanical pullout tests were undertaken at room temperature $\left(22^{\circ} \mathrm{C}\right)$. After aligning the Insight Material Testing System and placing the polyurethane foam in a pullout-holding device, pullout force (F) was applied vertically to the screw at a rate of $5 \mathrm{~mm}$ per minute until pullout was noted (Fig. 4). The strengths of the different screws are presented in Fig. 2.

The statistical analysis, conducted using Statgraphics Centurion XVI software (Statpoint Technologies Inc., Warrenton, USA), consisted of an analysis of variance (ANOVA) with the screw manufacturers as the factors. Next, comparisons between self-tapping vs self-drilling screws were performed by t- test. A p-value below 0.05 was considered significant.

\section{Results}

None of the $1.5 \mathrm{~mm}$ or $2.0 \mathrm{~mm}$ diameter screws fractured during the tests; in each case, failure of the polyurethane foam was observed before any evidence of damage to the screw construction was noted. After the tests, the screws were removed along with the surrounding polyurethane in the threads.

Table 1. Average ( \pm standard deviation) pullout strength (in newtons) for the screws investigated in the study

\begin{tabular}{|c|c|c|c|c|c|}
\hline \multirow{2}{*}{ Manufacturer } & \multicolumn{2}{c|}{ Micro-system (diameter $1.5 \mathrm{~mm}$ ) } & \multicolumn{2}{c}{ Mini-system (diameter $2.0 \mathrm{~mm}$ ) } \\
\cline { 2 - 5 } & $6 \mathrm{~mm}$ self-drilling & $6 \mathrm{~mm}$ self-tapping & $6 \mathrm{~mm}$ self-drilling & $6 \mathrm{~mm}$ self-tapping & $16 \mathrm{~mm}$ self-tapping \\
\hline DePuy Synthes & $253.6 \pm 4.39$ & $226.0 \pm 7.52$ & $291.6 \pm 11.22$ & $152.2 \pm 14.58$ \\
KLS Martin & $250.6 \pm 16.04$ & $180.8 \pm 14.25$ & $320.8 \pm 9.09$ & $213.2 \pm 7.79$ \\
Medartis & $211.2 \pm 9.88$ & $188.6 \pm 6.07$ & $293.2 \pm 6.83$ & $228.8 \pm 9.73$ \\
Total & $238.47 \pm 22.51$ & $198.47 \pm 22.40$ & $301.87 \pm 16.29$ & $198.07 \pm 35.72$ \\
\hline
\end{tabular}


The results of experiment are presented in Table 1 . Among the self-tapping $6 \mathrm{~mm} \times 1.5 \mathrm{~mm}$ microscrews, the DePuy Synthes screws had the highest average pullout force $(F=29.53 ; p<0.001)$. Among the self-drilling screws $6 \mathrm{~mm} \times 1.5 \mathrm{~mm}$ screws, the KLN Martin and DePuy Synthes screws both had an average score of $\mathrm{F}=22.44$, which was significantly better than the Medartis screws $(\mathrm{p}<0.001)$. Among the self-tapping $6 \mathrm{~mm} \times 2.0 \mathrm{~mm}$ miniscrews, Medartis achieved the highest scores $(\mathrm{F}=66.77$; $\mathrm{p}<0.001$ ), but among the self-drilling $6 \mathrm{~mm} \times 2.0 \mathrm{~mm}$ screws the KLS Martin screws had the best results $(\mathrm{F}=15.84 ; \mathrm{p}<0.001)$. Finally, among the $16 \mathrm{~mm} \times 2.0 \mathrm{~mm}$ self-tapping screws for the lag technique, all 3 manufacturers' screws were equal $(\mathrm{F}=0.59 ; \mathrm{p}=0.578)$.

All the self-drilling $6 \mathrm{~mm}$ screws required higher pullout force than self-tapping ones in both the $1.5 \mathrm{~mm}$ system $(\mathrm{t}=4.88 ; \mathrm{p}<0.0001)$ and the $2.0 \mathrm{~mm}$ system $(\mathrm{t}=10.24$; $\mathrm{p}<0.00001)$.

\section{Discussion}

The screws evaluated in this study can be used in most cases of maxillofacial trauma, but are especially suitable for condylar fractures. The results of this study demonstrate superior screw types that offer doctors and clinicians opportunities to use less equipment and fewer procedures with no detriment to screw pullout strength. In biomechanical test environments, human cadaver bone can successfully be replaced with fixed polyurethane foam, as they are almost identical in terms of the results. ${ }^{7}$ Clinical bone conditions have been simulated using artificial bone material to research dental implant stability. ${ }^{8}$

A screw's insertion torque and the force of pullout constitute the main determinants of how strong a screw is (and can be) fixed. ${ }^{9}$ Maxillofacial screws have been studied with regard to geometry and materials, focusing on how each factor (the pitch, number of threads, fillet angle, etc.) performs and how multiple factors interact. ${ }^{10} \mathrm{~A}$ difference in surface properties can have profound effects on bone attachment. Aspects such as the quality, density and number of bone structures (or, in this study, polyurethane foam) play a role when measuring the pullout strength of a screw, ${ }^{11}$ but it appears that the strength itself is commensurate to the quantity of bone volume separating the threads. $^{12}$

Self-drilling miniscrews do not have a long history, being a recent invention. Their tip is sharp and pointed, and during insertion they follow the rotational axis and enter the bone as far as the screw head without any drilling whatsoever. ${ }^{13}$ As Pitzen et al. noted, axial starting load is very sensitive to the design of the screw tip. ${ }^{14}$ This is of utmost importance at the beginning of bone fixation, when any wobbling of the screws can ruin open rigid fixation. ${ }^{15}$

Self-drilling and self-tapping screws were initially developed for remediating damage to the maxillofacial region.
The aim of introducing them was to reduce the necessary equipment and doctor/clinician activities without negatively impacting the pullout strength of screws. ${ }^{13}$ In this study it was observed that self-drilling screws had higher pullout strength than self-tapping screws. How screw anchorage is impacted depends directly on how the screw thread surface and the adjacent bone interact: The higher degree of interaction between the bone and the screw, and denser bone adjacent to the thread, contribute to the higher pullout strength of self-drilling screws.

This conforms with the findings of research into the biochemistry and histomorphometry of self-drilling and self-tapping screws used in maxillofacial surgical interventions. ${ }^{16}$ Should a pilot hole be used, and should it be smaller than the internal screw diameter, there is a possibility of an increase in radial displacement and blockage (impaction) of cancellous bone while the screw (especially the core) is driven into the bone itself. This, in turn, involves more interaction between the screw and the adjacent bone and more bone makes its way into the thread. There is insufficient research into the histomorphometry of screw-bone interaction, but pressure exerted on cancellous bone by the screw as it is driven into the bone is regarded as a factor that increases density and pullout strength, which purportedly explains why screw pullout strength is higher in screws with cone-shape pedicles than in the non-tapping equivalent. ${ }^{17}$ Self-drilling screws necessitate more interaction with the bone than screws that need drilling. More debris is transported and deposited around a self-drilling screw, since its shaft is coneshaped. ${ }^{18}$ Research shows that self-drilling screws interact with the adjacent bone to a high degree, but the bone does not undergo significant thermal damage. ${ }^{13,18,19}$ In the present study, the comparative analysis of the pullout strength of self-drilling and self-tapping screws revealed higher strength in the former, which is due to the higher degree of interaction between the bone and thread (or, in the present study, the greater quantity of polyurethane foam in the thread). ${ }^{16}$ In clinical applications, self-drilling screws should be used carefully, especially in $1.5 \mathrm{~mm}$ diameter systems, due to the possibility of screw head damage.

For mandible injuries, Medartis opted for the lag screw technique, hence that manufacturer is the most reliable in the $16 \mathrm{~mm}$ screw competition. On the other hand, DePuy Synthes took on traditional rigid monocortical fixation in the midface region, and achieved excellent results with their $6 \mathrm{~mm} \times 1.5 \mathrm{~mm}$ self-tapping screws. The superior screw-bone interaction of self-drilling screws compared to self-tapping screws and more actual bone in the threads of screws driven without drilling corroborates the present study's findings that both screw's holding strength is sufficient in test environments. These results have considerable significance from the perspective of osteosynthesis in regions with thin cortical bone, such as the central midface region. ${ }^{18}$ 
The results of this study show that the 3 screw types are each well suited for different skull regions. KLS Martin $6 \mathrm{~mm} \times 2.0 \mathrm{~mm}$ self-drilling screws can be driven into the bone without predrilling, which results in the highest stability. Inserting self-drilling screws is straightforward and is recommended in the central midface region, ${ }^{18}$ making $6 \mathrm{~mm} \times 1.5 \mathrm{~mm}$ DePuy Synthes screws the best choice. Medartis $6 \mathrm{~mm} \times 2.0 \mathrm{~mm}$ self-tapping screws are the ideal choice for mandible osteosynthesis, and in the lateral midface. However, the use of self-drilling screws in the mandibular angle region is not recommended. ${ }^{20}$

Cone-shaped screws perform best in cancellous bone in all specifications ${ }^{21}$ thanks to their design: A conical selfdrilling screw has superior primary stability to its cylinder-shaped self-tapping equivalent. ${ }^{22}$ Self-tapping screws in pre-drilled pilot holes achieved the best results when used with high-thickness cortical bone, in contrast to selfdrilling and self-tapping screws, which behave best when inserted into thin bone. ${ }^{21}$

It appears that both self-tapping and self-drilling screws offer a reliable level of anchorage. However, the superiority of the self-drilling type stems from the reduction in insertion time and effort, and the elimination of debris and thermal damage. Self-drilling screws also entail less morbidity, and eliminate the need for pre-drilling. Due to these benefits, they can effectively supersede self-tapping screws. ${ }^{22}$

To conclude, there is currently no universal screw for all maxillofacial applications. Moreover, there are significant differences in the fixing force among screws of the same diameter but originating from different manufacturers.

\section{References}

1. Motamedi MH, Dadgar E, Ebrahimi A, Shirani G, Haghighat A, Jamalpour MR. Pattern of maxillofacial fractures: A 5-year analysis of 8,818 patients. J Trauma Acute Care Surg. 2014;77:630-634.

2. Srinivasan I, Kumar N, Jaganathan U, Bhandari A. Miniplate for osteosynthesis in a 9-year-old with symphysis fracture: Clinical report. Int J Clin Pediatr Dent. 2013;6:213-216.

3. Valentino J, Levy FE, Marentette LJ. Intraoral monocortical miniplating of mandible fractures. Arch Otolaryngol Head Neck Surg. 1994;120:605-612.

4. Neff A, Dingiria F, Schütz K, Karoglan M, Steinhäuser E. Retentive values of different screw types in the spongious bone of the condylar head. Proceedings 18 EACMFS Congress, Barcelona, Spain, September 12-15, 2006.

5. Kozakiewicz $M$, Swiniarski J. "A" shape plate for open rigid internal fixation of mandible condyle neck fracture. J Cranio-Maxillofac Surg. 2014;42,730-737.

6. Barber FA. Pullout strength of bone-patellar tendon-bone allograft bone plugs: A comparison of cadaver tibia and rigid polyurethane foam. Arthroscopy. 2013;29:1546-1551.

7. Kim DS, Lee WJ, Choi SC, et al. Comparison of dental implant stabilities by impact response and resonance frequencies using artificial bone. Medical Engineering \& Phisics. 2014;36:715-20.

8. Ryken TC, Clausen JD, Traynelis VC, et al. Biomechanical analysis of bone mineral density, insertion technique, screw torque, and holding strength of anterior cervical plate screws. J Neurosurg. 1995;83:324-329.

9. Zanetti EM, Salaorno M, Grasso G, Audenino AL. Parametric analysis of orthopedic screws in relation to bone density. Open Med Inform J. 2009;3:19-26.
10. Cho W, Cho SK, Wu C. The Biomechanics of pedicle screw-based instrumentation. J Bone Jt Surg. 2010;92:1061-1065.

11. Benzel EC. Implant-bone interfaces. In Benzel EC, editor. Biomechanics of spinal stabilization. New York: Thieme 2011;155-170.

12. Heidemann W, Gerlach KL, Grobel KH, Köllner HG. Drill free screws: A new form of osteosynthesis screw. J Craniomaxillofac Surg. 1998;26:163-168.

13. Kincaid B, Schroder L, Mason J. Measurement of orthopedic cortical bone screw insertion performance in cadaver bone and model materials. Experimental Mechan. 2007;47:595-607.

14. Pitzen T, Franta F, Barbier D, Wolf-Ingo S. Insertion torque and pullout force of rescue screws for anterior cervical plate fixation in a fatigued initial pilot hole. J Neurosurg. 2004; 2:198-201.

15. Porto MA, Silva $P$, Rosa $R$, et al. Experimental in vivo acute and chronic biomechanical and histomorphometrical comparison of self-drilling and self-tapping anterior cervical screws. Eur Spine J. 2012;21:956-963.

16. Silva P, Rosa R, Shimano A, Defino H. Effect of pilot hole on biomechanical and in vivo pedicle screw-bone interface. Eur Spine J. 2013;22:1829-1836.

17. Heidemann W, Terheyden H, Gerlach KL. In vivo studies of screwbone contact of drill-free screws and conventional self-tapping screws. Mund Kiefer Gesichtschir. 2001;5:17-21.

18. Kim JW, Ahn SJ, Chang YII. Histomorphometric and mechanical analysis of the drill-free screw as orthodontic anchorage. Am J Orthod Dentofacial Orthop. 2005;128:190-194.

19. Heidemann W, Gerlach KL. Clinical applications of drill free screws in maxillofacial surgery. J Craniomaxillofac Surg. 1999;27:252-255.

20. Lohr J, Gellrich NC, Buscher P, Wahl D, Rahn BA. Vergleichende Invitro-Untersuchungen von selbstbohrenden und selbstschneidenden Schrauben. Histomorphologische und physikalisch-technische Untersuchungen des Lagerknochens. Mund Kiefer Gesichtschir. 2000;4:159-163.

21. Mischkowski RA, Kneuertz P, Florvaag B, Lazar F, Koebke J, Zöller JE. Biomechanical comparison of four different miniscrew types for skeletal anchorage in the mandibulo-maxillary area. Int J Oral Maxillofac Surg. 2008;37:948-954.

22. Gupta N, Kotrashetti SM, Naik V. A comparitive clinical study between self tapping and drill free screws as a source of rigid orthodontic anchorage. J Maxillofac Oral Surg. 2012;11: 29-33. 
